\title{
On the low temperature resistivity measurement of CdSe thin film
}

\author{
R.K.Shah ${ }^{1 *}$, H.O.Parmar ${ }^{1}$, H.S.Patel ${ }^{2}$,R.J.Pathak ${ }^{3}$, V.M.Pathak $^{4}$ \\ ${ }^{1}$ Arts, Science and R. A. Patel Commerce College, Bhadran, Dist. Anand, Gujarat. \\ ${ }^{2}$ Arts,Science and Commerce College, Borsad, Dist. Anand, Gujarat. \\ ${ }^{3}$ R.R.Mehta College of Science, Palanpur, Dist.Banaskantha, Gujarat. \\ ${ }^{4}$ Departmentment of Physics, Sardar Patel University, Vallabh Vidyanagar, Gujarat.
}

\begin{abstract}
Most group II-VI compounds are direct band gap semiconductors with high optical absorption and emission coefficients .Cadmium Selenide is a leading candidate with high potential towards many applications. The authors present their investigations dealing with preparation and some electrical characterization of the CdSe thin films. The films were deposited onto a well-cleaned glass substrates using thermal evaporation technique. The dependence of electrical resistivity of CdSe thin film in low temperature range has been studied.
\end{abstract}

Keywords: Cadmium Selenide, thermal evaporation technique, thin film, electrical resistivity

\section{INTRODUCTION}

Group II-VI compounds have been studied intensively recently because of their potentials for wide range of applications. These compounds has been studied in crystal as well as thin film form .This is because large uniform areas would prove extremely useful in the preparation of image intensifiers and photo voltaic devices. Amongst these Group II-VI compounds Cadmium Selenide (CdSe) is an important and most promising material .In the much current research, researchers are interested to understand different properties of Cadmium Selenide from its applications point of view such as thin film transistors[1], thin film solar cells[2-3], photodetectors[4-5], heterojunction solar cells[6] and various optoelectronic devices[7].Several methods have been applied for the preparation of CdSe thin films such as vacuum evaporation technique[8-10], chemical vapor deposition[11], chemical deposition[12-15],SILAR method and electrodeposition method[17-18].Much current research has focused on electrical properties of CdSe thin films. The electrical characterization of any material is very important because it gives an idea about various important parameters related to the material. On the basis of this, in the present paper, the authors present their investigations on the preparation of CdSe thin films and the effect of low temperature on the electrical resistivity of the CdSe thin films.

\section{EXPERIMENTAL}

The deposition technique can be chosen depending upon the type of material and its intended use for various applications. The physical vapour deposition technique is the simplest and widely used technique for deposition of semiconducting thin films. The same technique i.e. the thermal evaporation technique has been adopted here for the deposition of CdSe thin films. Stoichiometric CdSe powder having purity around $99.99 \%$ was kept in a molybdenum boat. Thin film of CdSe have been deposited at a pressure better than $10^{-5}$ torr in a vacuum coating unit (Hind High Vac, Bangalore, India).The deposition of the thin films has been carried out on a pre-cleaned glass slides used as the substrates. Prior to deposition, the glass slides were cleaned with acetone which was followed by the washing with distilled water. The thickness has been controlled during the deposition process \& measured using quartz crystal thickness monitor. The thickness of the film has been found to be $3 \mathrm{k} \AA$.

The variation in electrical resistivity with temperature in a low temperature range has been investigated on CdSe thin films using van der Pauw method. The contacts have been prepared using silver paste. These investigations have been carried out below room temperature using liquid $\mathrm{N}_{2}$ cryostat. The resistivity has been measured within the temperature range from $223 \mathrm{~K}-300$ $\mathrm{K}$. The temperature was controlled and monitored using the cryocontroller throughout the investigations. 


\section{www.ijtsrd.com}

\section{RESULT AND DISCUSSION}

CdSe thin films have been obtained in present investigations using the physical vapour deposition technique having thickness around $3000 \AA$ A. The thoroughly pre-cleaned micro glass slides have been used as substrates. The van der Pauw method has been used to study the behaviour of the electrical resistivity of
CdSe thin films at low temperature ranging from $223 \mathrm{~K}-300$

K. The experimental set up explained above has been used for these investigations. The results obtained for CdSe thin films apparently show that as the temperature decreases, the resistivity increases, as expected according to the semiconducting behaviour of cadmium selenide.

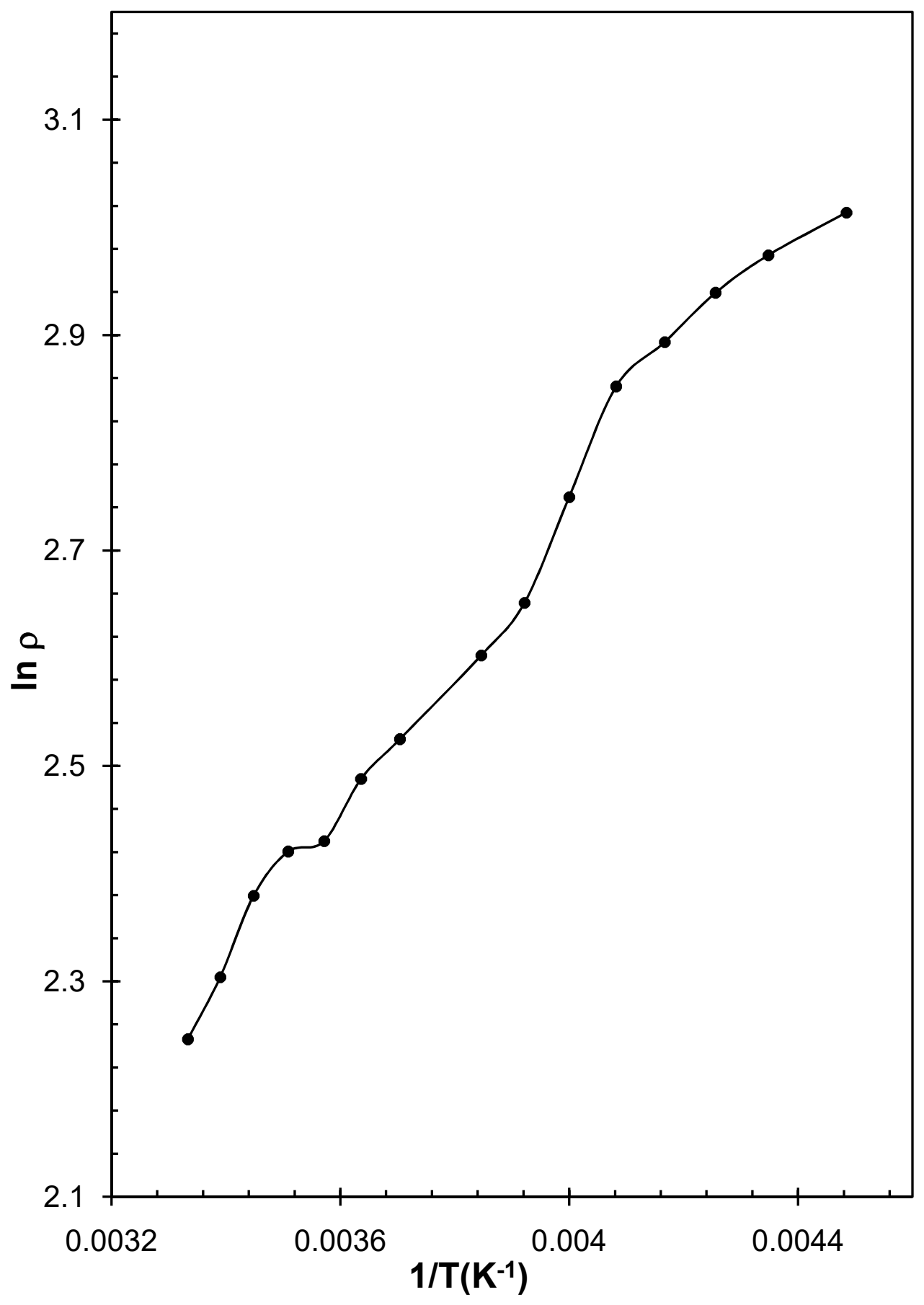

Fig 1 . The graph of $\ln \rho$ vs $1 / \mathrm{T}$ 
The graphical representation of the results has been shown in

Fig. 1 which is again depicting a non-linear behaviour. This non-linear behaviour has also been attributed to the hopping of carriers, the presence of exciton mechanism etc.

Moreover from this graph the activation energy of the charge carriers has been calculated and has found to be around 0.1 $\mathrm{eV}$ within the range of temperature under investigations. Besides this the nature of the graph clearly indicates that the CdSe thin films prepared using thermal evaporation technique in present investigations exhibits semiconducting behavior.

\section{CONCLUSION}

The present study indicates that the physical vapour deposition technique can be successfully employed for the preparation of CdSe thin films on glass substrates. CdSe thin films having thickness $3 \mathrm{k} \AA$ in present investigations possess activation energy $0.1 \mathrm{eV}$ and shows a semiconducting behaviour at low temperature range.

\section{REFERENCES}

[1] Van Claster A; Vervact A.; De Rycke J. and Bates J.D., J.Cryst. Growth, 1998, 86,924.

[2] S. M. Pawar; A.V. Moholkar; K.Y. Rajpure and C. H. Bhosale,

Sol. Energy Mater. Sol. Cells,2008, 92, 45-49.

[3] P. Mahawela; S. Jeedigunta; S. Vakkalanka; C.S. Ferekides and D. L. Morel

Thin Solid Films, 2005, 480-481, 466-470.

[4] S. Lou; C. Zhou; H. Wang; H. Shen; G. Cheng and Z. Du, Mater. Chem. Phys., 2011, 128, 483-488.

[5] Konstantatos G.; Howard I.; Fischer A.; Hoogland S.; Clifford J.; Klem E.; Levina L. and Sargent E.H., Nature, 2006, 442,180-183.

[6] L. Tian; H. Yang; J. Ding; Q. Li;Y. Mu and Y. Zhang, Curr. Appl. Phys., 2014, 14, 881.

[7] V.Saaminathan and K.R.Murali, 2005, J.Cryst.Growth, 2005, 279,229-240.

[8] N.C. Parakh and J.C. Garg Indian J. Pure \& Appl. Phys., 24 (1986) 154.

[9] F. Raoult, B. Fortin and Y. Colin Thin Solid Films, 182 (1989) 1.

[10] A.O. Oduor and R.D. Gould Thin Solid Films, 317 (1998) 409.

[11] T.M. Razikov Thin Solid Films, 164 (1988) 301.

[12] F. Trojanek, R. Cingolani, D. Cannoletta, P. Nemee, E. Uhlirova, J. Rohovec and P. Maly

J. Cryst. Growth (Netherlands), 209 (2000) 695.

[13] S.S. Kale and C.D. Lokhande Mater. Chem. Phys. (Switzerland), 62 (2000) 103.

[14] O. Savadogo 361.

Sol. Energy Mater. Sol. Cells (Netherlands), 52 (1998)

[15] O. Portillo - Moreno, O. Zelaye - Angel, R. Lozada Morales and M. Rubin - Falfan

Opt. Mater. (Netherlands), 18 (2002) 383.

[16] Yunus Akathun; M.Ali Yildirim; Aytune Ates and Muhammet Yildirim.Optics

Communication, 2008, 284, 2307.

[17] S. Mishra, R.K. Pandey, P. Sahu, S. Tiwari \& B.P. Chandra

Sol. Energy Mater. Sol. Cells (Netherlands), 60 (2000) 59.

[18] V. Subramanian, K.R. Murali \& V. Swaminathan Thin solid Films (Switzerland), 359 (2000) 113. 